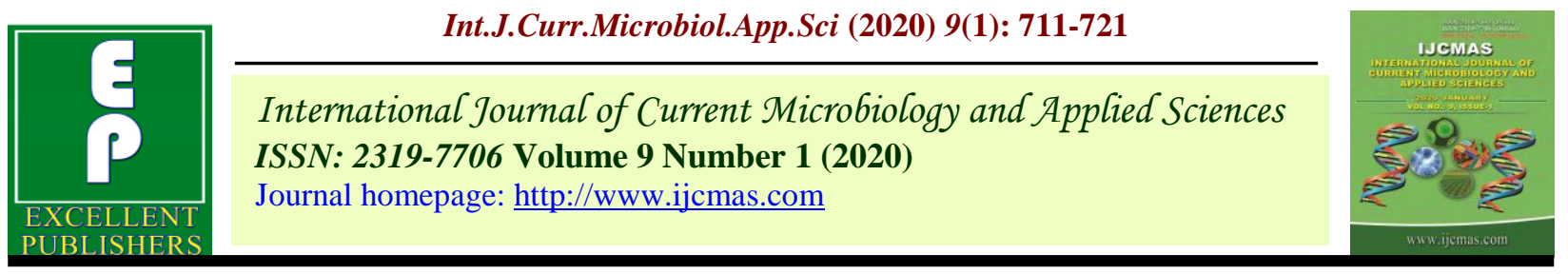

Original Research Article

https://doi.org/10.20546/ijcmas.2020.901.077

\title{
Evaluation of Antioxidant Activity of Developed Instant Soup Mixes using Vegetable Leaf Powders from Unconventional Greens
}

\author{
Nidhi Joshi*, Kiran Bains and Harpreet Kaur \\ ${ }^{1}$ Department of Food and Nutrition, Punjab Agricultural University, Ludhiana-141004, \\ Punjab, India \\ *Corresponding author
}

Keywords

Antioxidant activity, Instant soup mix, Unconventional greens, Vegetable leaf powder

Article Info

Accepted:

15 December 2019 Available Online: 20January 2020

\section{A B S T R A C T}

The present study was carried out to formulate instant soup mixes using vegetable leaf powders from unconventional greens namely turnip (Brassica rapa), radish (Raphanus sativus), cauliflower (Brassica oleracea) and carrot (Daucus carota) and to measure their antioxidant activity along with organoleptic characteristic. The two formulations of instant soup mix which had been enriched with either turnip leaf powder or radish leaf powder at a 5\% level had higher antioxidant activity than the formulation where no vegetable leaf powder had been incorporated i.e. 39.27 vs 41.58 and $44.80 \%$, respectively. The retention of antioxidant activity of the soup mixes enriched with either turnip, radish or carrot leaf powders did not reduce significantly after storage of two months. The antioxidant activity of ten commercially available soup mixes varied between 18.64 to $34.45 \%$ with the mean value of $25.21 \%$. The three optimized soup mix formulations with or without the vegetable leaf powders showed a significantly $(\mathrm{p} \leq 0.05)$ higher antioxidant activity in comparison to the commercially available soup mixes. The sensory characteristics of instant soup mix enriched with either turnip or radish leaf powder had comparable acceptability in comparison to the formulation where no leaf powder was incorporated. The turnip and radish leaf powder enriched soup mixes possessed an excellent antioxidant activity with optimum sensory characteristics and consumer acceptability.

\section{Introduction}

Green leafy vegetables had enormous nutritive potential and can be used in the prevention of radical-induced diseases. About 600 species constitute the global diversity in vegetable crops but only one fourth is utilized as a major vegetable crop and rest are named 
as underutilized vegetables (Pandey et al., 2014). Unconventional greens are a rich source of phytochemicals and phenolic compounds that contribute to the antioxidant activity in the diet (Uusiku et al., 2010). The nutritive potential of some less commonly used and inexpensive vegetable greens has not yet been adequately studied. These vegetable byproducts are easily available in the market at no cost and not utilized by general masses rather used for cattle feed due to lack of awareness about their nutritional value.

Today's health-conscious consumers demand products that are convenient and promote health. There is a demand for high quality, convenient, shelf-stable and ready-to-use processed food products. Instant soups fall in the category of key dried foods. Soup powders are convenient food items and comprised of ingredients such as corn starch, spices, salt, flavors, and flavor enhancers. Instant soup mixes gained popularity among all dehydrated products as they are very practical in preparation and available in various packages. Soups are consumed for their nutritional benefits and by patients whose intake of solid is reduced due to various physiological conditions. Soup formulations can be made nutritionally balanced by incorporating whole cereals, vegetables, and pulses. Instant soup mixes can be used as an alternative food for breakfast as it can fulfill the adequacy of energy and nutrient required by the body (Sunyoto and Futiawati, 2012). Being a liquid-food, a good soup powder should be cooked within minimum time, retaining nutrients and palatability almost similar to freshly cooked products (Abeysinghe and Illeperuma, 2006). Dried soup mixes have an advantage of protection from oxidative and enzymatic spoilage and flavor stability for longer periods up to one year at room temperature (El Wakeel, 2007). They do not need refrigeration; exert lightweight for shipping and available all around the year (Rekha et al., 2010). Functional ingredients can be incorporated into soup powder to provide health benefits.

Unconventional leafy greens being a reservoir of essential vitamins, micronutrients, and other phytochemicals have the potential to play a major role in strategies to attain nutritional security and can be explored to prevent degenerative diseases. Unconventional leafy greens can be incorporated into existing products as natural fortificants and can be used in the formulation of health foods. Dehydrated unconventional leafy greens are a concentrated source of micronutrients and bioactive compounds, therefore, can be used to supplement traditional recipes as well as commercially available convenience foods (Singh et al., 2014). The basic idea is to find novel methods by which consumption of greens can be increased. Vegetable powders can be produced with a view of good consumer appeal and varied use. There are several soup mixes available commercially; however unconventional vegetable greens have not been explored for soup mix preparation. Vegetable powders prepared from such greens with optimum antioxidant potential can be formulated for standardizing soup mixes as a convenience food with sufficient healthpromoting properties.

\section{Materials and Methods}

\section{Procurement of vegetable greens}

Unconventional leafy greens mainly considered as vegetative waste of common vegetables namely, turnip (Brassica rapa), radish (Raphanus sativus), cauliflower (Brassica oleracea) and carrot (Daucus carota) were procured from a local vegetable market in the early morning. 


\section{Preparation of vegetable leaf powder}

The fresh green leaves of the selected vegetables were washed with tap water to remove soil or other impurities. The leaves were chopped with a knife and processed immediately in order to prevent chemical changes during storage if any. Vegetable leaves were dried in a hot air oven at optimized temperature and time for maximum antioxidant activity retention. Turnip and radish leaves were dried at $40^{\circ} \mathrm{C}$ for 12 and 14 hours respectively. Cauliflower and carrot leaves were dried at $50^{\circ} \mathrm{C}$ for 10 and 12 hours respectively. Dehydrated vegetable leaves were grounded finely in a grinder and stored in airtight jars until further use.

\section{Procurement of raw materials}

Lentils, cornflour (Weikfield),black pepper powder (Catch brand), red Chilli powder (Catch brand), salt (Tata brand), ghee (Britannia), garlic powder (Kitchen Master's brand), tomato powder (Tassyam brand) and onion powder (Tassyam brand) and ten popular vegetarian soup mixes from the brands namely Knorr, Bambino, Ching's, Tasty Treat, Zoopy and Keya were procured from the local market.

\section{Preparation of lentil powder}

Five hundred grams of lentils were soaked in one liter of water for two hours. Soaked lentils were pressure cooked using one liter of water at 15 pounds pressure for 10 minutes. Cooked lentils were dehydrated in a hot air oven at $60^{\circ} \mathrm{C}$ till constant weight was obtained. Dehydrated lentils were grounded finely in a grinder, sieved and stored in airtight jars until use.

\section{Formulations of instant soup mix}

The standardized recipe without the incorporation of vegetable leaf powder was taken as control. Three levels of incorporation of the formulated vegetable leaf powder prepared from turnip, radish, cauliflower, and carrot leaves i.e. 2.5, 3.75 and 5\% were decided on the basis of preliminary testing. Twelve formulations of soup mix were made using vegetable leaf powders. The proportion of ingredients for the formulation instant soup mix has been shown in table I.

\section{Sensory evaluation of the selected instant soup mixes}

The instant soup mixes incorporated with three levels of vegetable leaf powder were selected for sensory evaluation on the basis of their antioxidant activity. For the reconstitution, $25 \mathrm{~g}$ of soup mix was dissolved in $280 \mathrm{ml}$ of water for serving two persons. The whole mass was then boiled and cooked for 10 minutes on slow fire with constant stirring. The soup was served hot to a panel of ten semi-trained panelists. The panelists were asked to score the samples on the basis of their appearance, consistency, mouthfeel, taste, flavor and overall acceptability by using a scorecard of ninepoint Hedonic Rating Scale where 9 indicated "like extremely" and 1 indicated "dislike extremely".

The consumer acceptability of selected soup mixes was carried out among fifty subjects to determine the degree of liking of product. The subjects were hostel residing girl students of age group 18 to 25 years. Each consumer was served with the selected soups and asked to evaluate them for their overall acceptability on an evaluation card provided to them. Their preference for the purchase of the soup mix if available in the market was also recorded.

\section{Antioxidant activity}

The free radical scavenging activity was determined by using the DPPH assay (0.1mM) (Dehshahri et al., 2012). Two grams 
of the sample was extracted with $20 \mathrm{ml}$ of methanol by shaking for two hours. The extraction process was repeated twice. The extract was pulled together and centrifuged at $10000 \mathrm{rpm}$ for 15 minutes. The supernatant was stored at $-20^{\circ} \mathrm{C}$ till analysis. $100 \mu \mathrm{l}$ of the aliquot of the extract was taken in test tubes and added $2.9 \mathrm{ml}$ of DPPH solution. The mixture was vortexed for 1 minute and incubated in dark for 3 minutes. The discoloration of DPPH was measured against blank at $517 \mathrm{~nm}$. The DPPH scavenging effect was measured using by the formula: Percent inhibition $=A_{B}-A_{A} / A_{B} \times 100$

Where, $\mathrm{A}_{\mathrm{B}}=$ absorbance of blank; $\mathrm{A}_{\mathrm{A}}=$ absorbance of the sample

\section{Statistical analysis}

Mean and standard deviations for the various parameters were computed. Analysis of Variance (ANOVA) was employed using Microsoft Excel (2003) Statistical Analysis Tool Pack. Least Significant Difference (LSD) at 5\% was calculated for the comparison among the parameters.

\section{Results and Discussion}

\section{Antioxidant activity of instant soup mix formulations using vegetable leaf powders}

Thirteen formulations of instant soup mix were prepared with or without incorporation of turnip, radish, cauliflower, and carrot vegetable leaf powder at different levels. The composition and antioxidant activity of these formulations have been shown in table II. The results indicated that in comparison to formulation $F_{1}$, where no vegetable leaf powder has been incorporated, formulation $\mathrm{F}_{4}$ and $F_{7}$ which had been supplemented with turnip leaf powder and radish leaf powder at $5 \%$ level each had significantly $(p \leq 0.05)$ higher antioxidant activity in comparison to
$F_{1}(39.27 \%)$, the antioxidant activity of two formulations being 41.58 and 44.80 percent, respectively. Two soup mix formulations with turnip and radish leaf powder incorporated at $5 \%$ showed higher antioxidant activity as compared to control and rest of the formulations. Rekha et al., (2010) reported an enhancement of the antioxidant activity of soup mix when it was enriched with dried dill leaves. Janci Rani and Sarojini (2012) reported antioxidant activity of $23.19,38.1$ and $41.72 \%$ in soup mix incorporated with Brahmi leaf powder, moringa leaf powder and Brahmi moringa-aonla powder, respectively. The soup mix formulations in the present study reported higher antioxidant activity as compared to those reported in the literature.

\section{Effect of storage on antioxidant activity of formulated instant soup mixes}

Thirteen formulations of instant soup mixes were stored under room temperature and analyzed for their antioxidant activity after a period of two months, the results of which have been shown in Table III. The results revealed that the antioxidant activity of the formulations did not decrease significantly except the three formulations i.e. $\mathrm{F}_{8}, \mathrm{~F}_{9}$ and $\mathrm{F}_{10}$. A significant $(\mathrm{p} \leq 0.05)$ reduction was observed in antioxidant activity after two months in case of these three formulations where cauliflower leaf powder was incorporated at 2.5, 3.75 and 5\% level, respectively. Wadikar and Premavalli (2013) reported shelf life of 6 months in instant soup mixes developed from aromatic leaves of Coleus aromaticus stored at room temperature. Singh et al., (1999) reported a shelf life of 8 months for mushroom-whey soup powder stored at $30^{\circ} \mathrm{C}$. The results showed that the soup mix formulations $\mathrm{F}_{4}$ and $\mathrm{F}_{7}$ which possessed maximum antioxidant activity can be stored for a period of two months without any significant reduction in their antioxidant activity. 
Comparison of antioxidant activity of standardized instant soup mix with that of commercial soup mixes

Ten instant soup mixes were randomly picked up from the market and analyzed for their antioxidant activity. The results in table IV showed that the antioxidant activity of commercially available soup mixes varied between 18.64 to $34.45 \%$ with the mean value of $25.21 \%$. A significant $(\mathrm{p} \leq 0.05)$ variation in the antioxidant activity of commercially available instant soup mixes has been observed. The three soup mix formulations with or without the dried leaf powder showed a significantly $(\mathrm{p} \leq 0.05)$ higher antioxidant activity in comparison to commercially available soup mixes, the antioxidant activity is 41.58 and $44.80 \%$ for formulated instant soup mixes enriched with $5 \%$ of turnip and radish leaf powder. The antioxidant activity of the soup formulations enriched with either turnip and radish leaves showed higher antioxidant activity as compared to the one reported in the literature. Janci Rani and Sarojini (2012) reported antioxidant activity of $16.54 \%$ in commercial soup mix and 23.19 to $38.1 \%$ of antioxidants in soup mixes formulated with dried Brahmi leaves and moringa leaves.

Sensory evaluation and consumer acceptability of instant soup mix enriched with vegetable leaf powders

The reconstituted turnip and radish leaf powder enriched soup mixes had higher antioxidant activity in comparison to cauliflower and carrot leaves. Moreover, the retention of antioxidant activity of the soup mixes enriched with turnip and radish leaf powders was superior as compared to the soup mixes enriched with either cauliflower and carrot leaf powder. Hence, for further testing of sensory quality, the turnip and radish enriched soup mixes were subjected to sensory evaluation by a group of semi-trained panelists. The results of the sensory evaluation have been shown in Table V. Formulation $F_{1}$, where no leaf powder has been incorporated has been considered as control. This formulation had the highest overall acceptability with a mean score of 7.75. Among the other formulations, the mean overall acceptability of instant soup mix was highest for $\mathrm{F}_{2}$ enriched with $2.5 \%$ turnip leaf powder followed by $\mathrm{F}_{4}$ enriched with $5 \%$ turnip leaf powder and $\mathrm{F}_{3}$ enriched with $3.75 \%$ turnip leaf powder. Formulation $F_{1}$ scored highest for appearance, consistency and mouth feel whereas $\mathrm{F}_{2}$ scored highest for taste (7.82) and $F_{3}$ scored highest for the flavor (7.77).

The sensory evaluation of turnip and radish enriched instant soup mixes have clearly shown a non-significant difference of formulations supplemented with turnip leaf powder in comparison to formulation $F_{1}$ (control), in terms of appearance, consistency, mouthfeel, taste, flavor and overall acceptability. It has been observed that turnip leaf powder at all levels was acceptable. The overall acceptability ranged from 7.61 to 7.73. On the other hand, the mean overall acceptability was highest for instant soup mixes incorporated with radish leaf powder at a $2.5 \%$ level (7.65). The results of the statistical analysis showed that formulation where radish leaf powder was enriched at a $5 \%$ level, a significantly $(\mathrm{p} \leq 0.05)$ lower scores were observed for consistency, taste and overall acceptability in comparison to the formulation taken as control.

Table VI shows a comparison of sensory characteristics of instant soup mixes enriched with either turnip or radish leaf powder at a $5 \%$ level. The results revealed a nonsignificant difference in all the sensory characteristics as well as the overall acceptability of two soup mixes. However, 
the instant soup mix with turnip leaf powder had a higher score for overall acceptability as compared to the one supplemented with radish leaf powder.

Five percent level incorporation of Moringa olifera, Solanum tribatum, and Centeall asiatica leaves did not alter much of the sensory profile of soup mixes as observed by Chandramouli et al., (2012). Moringa leaves incorporated at $8.5 \%$ level in vegetable soup powder had higher acceptability as compared to locally available soup powders have been reported by Farzana et al., (2017). Wadikar and Premavalli (2013) formulated a soup mix from Coleus aromaticus (karpurvalli) which is an herb with aromatic leaves. The optimized karpurvalli soup mix with $6.4 \%$ of dehydrated leaves resulted in overall acceptability of 7.78

The consumer acceptability trial among fifty subjects was also carried out for the two instant soup mixes incorporated with turnip and radish leaf powder at a 5\% level. Table VII shows that the maximum number i.e. $57 \%$ liked the turnip leaf powder enriched instant soup mix extremely while $30 \%$ of them liked this soup very much. On the other hand, $30 \%$ of the subjects reported extreme liking for the soup supplemented with radish leaf powder, whereas $53 \%$ liked it very much. $97 \%$ of the subjects showed their preference for the purchase of instant soup mix enriched with turnip leaf powder and 83\% showed their preference for the purchase of instant soup mix incorporated with radish leaf powder. These results clearly indicated that instant soup mix supplemented with turnip leaf powder had superiority over radish leaf powder in terms of consumer acceptability and preference for purchase if available commercially.

Table.1 Standardized recipe of instant soup mixes

\begin{tabular}{|l|c|c|c|c|}
\hline \multirow{2}{*}{ Ingredients (g) } & \multirow{2}{*}{ Control } & \multicolumn{3}{c|}{ Level of vegetable leaf powder incorporation } \\
\cline { 2 - 4 } & & $\mathbf{2 . 5 \%}$ & $\mathbf{3 . 7 5 \%}$ & $\mathbf{5 \%}$ \\
\hline Lentil powder & 40 & 37.5 & 36.25 & 35 \\
\hline Dried leaf powder & - & 2.5 & 3.75 & 5 \\
\hline Corn flour & 5 & 5 & 5 & 5 \\
\hline Tomato powder & 18 & 18 & 18 & 18 \\
\hline Onion powder & 11 & 11 & 11 & 11 \\
\hline Garlic Powder & 10 & 10 & 10 & 10 \\
\hline Black pepper powder & 1.5 & 1.5 & 1.5 & 1.5 \\
\hline Red Chilli powder & 1.5 & 1.5 & 1.5 & 1.5 \\
\hline Table salt & 8 & 8 & 8 & 8 \\
\hline Ghee & 5 & 5 & 5 & 5 \\
\hline
\end{tabular}


Table.2 Standardization of instant soup mix using optimized vegetable leaf powder

\begin{tabular}{|c|c|c|c|c|c|c|c|c|c|c|c|c|c|c|}
\hline \multirow[t]{2}{*}{ Formulation } & \multicolumn{13}{|c|}{ Instant Soup Mix Composition (gm) } & \multirow{2}{*}{$\begin{array}{l}\text { Antioxidant } \\
\text { Activity (\%) }\end{array}$} \\
\hline & $\begin{array}{c}\text { Lentil } \\
\text { Powder }\end{array}$ & $\begin{array}{l}\text { Corn } \\
\text { Flour }\end{array}$ & $\begin{array}{l}\text { Tomato } \\
\text { Powder }\end{array}$ & $\begin{array}{l}\text { Onion } \\
\text { Powder }\end{array}$ & $\begin{array}{l}\text { Garlic } \\
\text { Powder }\end{array}$ & $\begin{array}{c}\text { Black } \\
\text { Pepper }\end{array}$ & $\begin{array}{c}\text { Red } \\
\text { Chilli }\end{array}$ & $\begin{array}{l}\text { Table } \\
\text { Salt }\end{array}$ & Ghee & TLP & RLP & CauLP & CaLP & \\
\hline $\begin{array}{c}\mathbf{F}_{1} \\
\text { (Control) }\end{array}$ & 40 & 5 & 18 & 11 & 10 & 1.5 & 1.5 & 8 & 5 & 0 & 0 & 0 & 0 & $39.27^{\mathrm{a}} \pm 0.48$ \\
\hline $\mathbf{F}_{2}$ & 37.5 & 5 & 18 & 11 & 10 & 1.5 & 1.5 & 8 & 5 & 2.5 & 0 & 0 & 0 & $39.67^{\mathrm{a}} \pm 0.30$ \\
\hline $\mathbf{F}_{3}$ & 36.25 & 5 & 18 & 11 & 10 & 1.5 & 1.5 & 8 & 5 & 3.75 & 0 & 0 & 0 & $40.10^{a} \pm 1.78$ \\
\hline $\mathbf{F}_{4}$ & 35 & 5 & 18 & 11 & 10 & 1.5 & 1.5 & 8 & 5 & 5.0 & 0 & 0 & 0 & $41.58^{b} \pm 0.32$ \\
\hline $\mathbf{F}_{5}$ & 37.5 & 5 & 18 & 11 & 10 & 1.5 & 1.5 & 8 & 5 & 0 & 2.5 & 0 & 0 & $37.59^{c} \pm 0.28$ \\
\hline $\mathbf{F}_{6}$ & 36.25 & 5 & 18 & 11 & 10 & 1.5 & 1.5 & 8 & 5 & 0 & 3.75 & 0 & 0 & $38.31^{\mathrm{c}} \pm 0.76$ \\
\hline $\mathbf{F}_{7}$ & 35 & 5 & 18 & 11 & 10 & 1.5 & 1.5 & 8 & 5 & 0 & 5.0 & 0 & 0 & $44.80^{d} \pm 1.10$ \\
\hline $\mathbf{F}_{8}$ & 37.5 & 5 & 18 & 11 & 10 & 1.5 & 1.5 & 8 & 5 & 0 & 0 & 2.5 & 0 & $35.36^{\mathrm{e}} \pm 0.43$ \\
\hline $\mathbf{F}_{9}$ & 36.25 & 5 & 18 & 11 & 10 & 1.5 & 1.5 & 8 & 5 & 0 & 0 & 3.75 & 0 & $36.12^{\mathrm{e}} \pm 0.25$ \\
\hline $\mathbf{F}_{10}$ & 35 & 5 & 18 & 11 & 10 & 1.5 & 1.5 & 8 & 5 & 0 & 0 & 5.0 & 0 & $37.24^{\mathrm{ct}} \pm 0.81$ \\
\hline $\mathbf{F}_{11}$ & 37.5 & 5 & 18 & 11 & 10 & 1.5 & 1.5 & 8 & 5 & 0 & 0 & 0 & 2.5 & $34.69^{\mathrm{eg}} \pm 0.84$ \\
\hline $\mathbf{F}_{12}$ & 36.25 & 5 & 18 & 11 & 10 & 1.5 & 1.5 & 8 & 5 & 0 & 0 & 0 & 3.75 & $34.77^{\mathrm{eg}} \pm 0.63$ \\
\hline $\mathbf{F}_{13}$ & 35 & 5 & 18 & 11 & 10 & 1.5 & 1.5 & 8 & 5 & 0 & 0 & 0 & 5.0 & $37.36^{\mathrm{ch}} \pm 0.38$ \\
\hline LSD at $5 \%$ & - & - & - & - & - & - & - & - & - & - & - & - & - & 0.95 \\
\hline
\end{tabular}

Notes: Values are Mean \pm SD; Mean of seven replicates

Superscripts with same alphabets imply non-significant difference at $5 \%$ level of significance

Superscripts with different alphabets imply significant difference at 5\% level of significance

TLP: Turnip leaf powder; RLP: Radish leaf powder; CauLP: Cauliflower leaf powder; CaLP: Carrot leaf powder 
Table.3 Effect of storage on antioxidant activity of formulated instant soup mixes

\begin{tabular}{|c|c|c|c|}
\hline \multirow[t]{3}{*}{ Formulation } & \multirow{2}{*}{\multicolumn{2}{|c|}{$\begin{array}{l}\text { Antioxidant activity (\%) } \\
\text { Storage Period, months }\end{array}$}} & \multirow[t]{3}{*}{ LSD at $5 \%$} \\
\hline & & & \\
\hline & $\mathbf{0}$ & 2 & \\
\hline $\mathrm{F}_{1}$ (Control) & $39.27 \pm 0.48$ & $38.23 \pm 0.87$ & NS \\
\hline $\mathrm{F}_{2}$ (TLP @ 2.5\%) & $39.67 \pm 0.30$ & $38.31 \pm 0.65$ & NS \\
\hline$F_{3}$ (TLP@3.75\%) & $40.10 \pm 1.78$ & $39.32 \pm 1.07$ & NS \\
\hline $\mathrm{F}_{4}(\mathrm{TLP} @ \mathbf{5 \%})$ & $41.58 \pm 0.32$ & $40.04 \pm 0.53$ & NS \\
\hline $\mathrm{F}_{5}(\mathrm{RLP} @ 2.5 \%)$ & $37.59 \pm 0.28$ & $36.16 \pm 0.67$ & NS \\
\hline F $_{6}($ RLP @ 3.75\%) & $38.31 \pm 0.76$ & $37.04 \pm 0.56$ & NS \\
\hline F $_{7}($ RLP @ 5\%) & $44.80 \pm 1.10$ & $42.72 \pm 1.89$ & NS \\
\hline $\mathbf{F}_{8}($ CauLP @ 2.5\%) & $35.36^{\mathrm{a}} \pm 0.43$ & $32.36^{b} \pm 0.42$ & 1.92 \\
\hline F9(CauLP @ 3.75\%) & $36.12^{\mathrm{a}} \pm 0.25$ & $33.45^{b} \pm 0.68$ & 1.11 \\
\hline $\mathbf{F}_{10}($ CauLP @ 5\%) & $37.24^{\mathrm{a}} \pm 0.81$ & $32.31^{b} \pm 0.49$ & 3.62 \\
\hline $\mathbf{F}_{11}($ CaLP @ 2.5\%) & $34.69 \pm 0.84$ & $33.04 \pm 1.67$ & NS \\
\hline $\mathbf{F}_{12}($ CaLP @ 3.75\%) & $34.77 \pm 0.63$ & $33.16 \pm 0.76$ & NS \\
\hline $\mathbf{F}_{13}($ CaLP @ 5\%) & $37.36 \pm 0.38$ & $36.10 \pm 0.45$ & NS \\
\hline
\end{tabular}

Notes: Values are Mean $\pm \mathrm{SD}$; Mean of seven replicates

NS: Non-significant

Superscripts with same alphabets imply non-significant difference at $5 \%$ level of significance

Superscripts with different alphabets imply significant difference at 5\% level of significance

TLP: Turnip leaf powder; RLP: Radish leaf powder; CauLP: Cauliflower leaf powder; CaLP: Carrot leaf powder

Table.4 Antioxidant activity of commercial and optimized instant soup mixes

\begin{tabular}{|c|c|}
\hline Soup Mix & Antioxidant Activity \\
\hline Commercial & $28.95^{\mathrm{a}} \pm 0.69$ \\
\hline $\mathbf{S}_{\mathbf{1}}$ & $29.43^{\mathrm{a}} \pm 1.02$ \\
\hline $\mathbf{S}_{\mathbf{2}}$ & $27.44^{\mathrm{ab}} \pm 0.30$ \\
\hline $\mathbf{S}_{\mathbf{3}}$ & $25.37^{\mathrm{c}} \pm 1.60$ \\
\hline $\mathbf{S}_{\mathbf{4}}$ & $34.45^{\mathrm{d}} \pm 0.80$ \\
\hline $\mathbf{S}_{\mathbf{5}}$ & $26.72^{\mathrm{ac}} \pm 1.83$ \\
\hline $\mathbf{S}_{\mathbf{6}}$ & $19.39^{\mathrm{e}} \pm 2.65$ \\
\hline $\mathbf{S}_{\mathbf{7}}$ & $19.51^{\mathrm{e}} \pm 0.59$ \\
\hline $\mathbf{S}_{\mathbf{8}}$ & $22.18^{\mathrm{f}} \pm 0.60$ \\
\hline $\mathbf{S}_{\mathbf{9}}$ & $18.64^{\mathrm{a}} \pm 0.86$ \\
\hline $\mathbf{S}_{\mathbf{1 0}}$ & $\mathbf{2 5 . 2 1} \pm \mathbf{5 . 1 3}$ \\
\hline $\mathbf{M e a n}^{\text {Optimized }}$ & \\
\hline $\mathbf{F}_{\mathbf{1}}(\mathbf{C o n t r o l})$ & $39.27^{\mathrm{f}} \pm 0.48$ \\
\hline $\mathbf{F}_{\mathbf{4}}$ (TLP @ 5\%) & $41.58^{\mathrm{g}} \pm 0.32$ \\
\hline $\mathbf{F}_{\mathbf{7}}$ (RLP @ 5\%) & $44.80^{\mathrm{h}} \pm 1.10$ \\
\hline LSD at 5\% & $\mathbf{1 . 8 5}$ \\
\hline
\end{tabular}

Notes: Values are Mean \pm SD; Mean of seven replicates

Superscripts with same alphabets imply non-significant difference at $5 \%$ level of significance Superscripts with different alphabets imply significant difference at 5\% level of significance TLP: Turnip leaf powder; RLP: Radish leaf powder 
Table.5 Sensory evaluation of instant soup mixes enriched with vegetable leaf powder of turnip and radish

\begin{tabular}{|c|c|c|c|c|c|c|}
\hline Product & Appearance & Consistency & Mouthfeel & Taste & Flavor & $\begin{array}{c}\text { Overall } \\
\text { acceptability }\end{array}$ \\
\hline$F_{1}($ Control $)$ & $7.91 \pm 0.30$ & $7.82 \pm 0.40$ & $\begin{array}{c}7.82 \pm \\
0.40\end{array}$ & $7.64 \pm 0.67$ & $7.55 \pm 0.69$ & $7.75 \pm 0.37$ \\
\hline $\begin{array}{c}\mathbf{F}_{2} \text { (TLP @ } \\
\mathbf{2 . 5 \%})\end{array}$ & $7.73 \pm 0.47$ & $7.64 \pm 0.50$ & $\begin{array}{c}7.73 \pm \\
0.47\end{array}$ & $7.82 \pm 0.40$ & $7.73 \pm 0.47$ & $7.73 \pm 0.31$ \\
\hline $\begin{array}{c}\mathbf{F}_{3} \text { (TLP @ } \\
3.75 \%)\end{array}$ & $7.55 \pm 0.52$ & $7.55 \pm 0.52$ & $\begin{array}{c}7.68 \pm \\
0.64\end{array}$ & $7.50 \pm 0.50$ & $7.77 \pm 0.61$ & $7.61 \pm 0.44$ \\
\hline $\begin{array}{c}\text { F }_{4} \text { (TLP } @ ~ \\
5 \%)\end{array}$ & $7.55 \pm 0.69$ & $7.73 \pm 0.65$ & $\begin{array}{c}7.73 \pm \\
0.90\end{array}$ & $7.45 \pm 1.04$ & $7.64 \pm 0.92$ & $7.62 \pm 0.74$ \\
\hline LSD at $5 \%$ & NS & NS & NS & NS & NS & NS \\
\hline$F_{1}($ Control $)$ & $7.91 \pm 0.30$ & $7.82^{\mathrm{a}} \pm 0.40$ & $\begin{array}{c}7.82 \pm \\
0.40\end{array}$ & $7.64^{a} \pm 0.67$ & $7.55 \pm 0.69$ & $7.75^{\mathrm{a}} \pm 0.37$ \\
\hline $\begin{array}{c}\mathbf{F}_{5}(\mathbf{R L P} @ \\
\mathbf{2 . 5 \%})\end{array}$ & $7.64 \pm 0.50$ & $7.73^{\mathrm{a}} \pm 0.47$ & $\begin{array}{c}7.50 \pm \\
0.67\end{array}$ & $7.77^{\mathrm{a}} \pm 0.41$ & $7.64 \pm 0.67$ & $7.65^{a} \pm 0.44$ \\
\hline $\begin{array}{c}\text { F }_{\mathbf{6}} \text { (RLP @ } \\
3.75 \%)\end{array}$ & $7.59 \pm 0.80$ & $\begin{array}{c}7.23^{\mathrm{ab}} \pm \\
0.75\end{array}$ & $\begin{array}{c}7.09 \pm \\
0.94\end{array}$ & $7.09^{\mathrm{ab}} \pm 0.70$ & $7.09 \pm 0.83$ & $7.22^{\mathrm{ab}} \pm 0.69$ \\
\hline $\begin{array}{c}\text { F }_{7}(\mathbf{R L P} @ \\
\mathbf{5 \%})\end{array}$ & $7.18 \pm 0.75$ & $7.18^{b} \pm 0.75$ & $\begin{array}{c}6.95 \pm \\
1.06\end{array}$ & $6.95^{\mathrm{b}} \pm 0.96$ & $7.09 \pm 0.83$ & $7.07^{\mathrm{b}} \pm 0.76$ \\
\hline LSD at $5 \%$ & NS & 0.53 & NS & 0.61 & NS & 0.50 \\
\hline
\end{tabular}

Notes: Values are Mean $\pm \mathrm{SD}$; Mean of 12 replicates

NS: Non-significant; TLP: Turnip leaf powder; RLP: Radish leaf powder

Superscripts with same alphabets imply non-significant difference at 5\% level of significance

Superscripts with different alphabets imply significant difference at 5\% level of significance

Table.6 Comparison of instant soup mixes incorporated with turnip leaf powder and radish leaf powder at $5 \%$ level

\begin{tabular}{|l|c|c|c|}
\hline \multicolumn{1}{|c|}{$\begin{array}{c}\text { Sensory } \\
\text { characteristics }\end{array}$} & \multicolumn{3}{|c|}{ Instant soup mix } \\
\hline Appearance & $7.55 \pm 0.69$ & $7.18 \pm 0.75$ & NSD at 5\% \\
\hline Consistency & $7.73 \pm 0.65$ & $7.18 \pm 0.75$ & NS \\
\hline Mouthfeel & $7.73 \pm 0.90$ & $6.95 \pm 1.06$ & NS \\
\hline Taste & $7.45 \pm 1.04$ & $6.95 \pm 0.96$ & NS \\
\hline Flavor & $7.64 \pm 0.92$ & $7.09 \pm 0.83$ & NS \\
\hline Overall Acceptability & $7.62 \pm 0.74$ & $7.07 \pm 0.76$ & NS \\
\hline
\end{tabular}

Notes: Values are Mean \pm SD; Mean of 12 replicates NS: Non-significant

TLP: Turnip leaf powder; RLP: Radish leaf powder 
Table.7 Consumer acceptability of selected instant soup mixes

\begin{tabular}{|c|c|c|}
\hline Degree of Liking (\%) & TLP @ 5\% & RLP @ 5\% \\
\hline Liked Extremely & 57 & 30 \\
\hline Liked Very Much & 30 & 53 \\
\hline Liked Moderately & 13 & 17 \\
\hline $\begin{array}{c}\text { Preference for purchase (\%) } \\
\text { if available commercially }\end{array}$ & 97 & 83 \\
\hline
\end{tabular}

Notes: TLP: Turnip leaf powder; RLP: Radish leaf powder

In conclusion, the soup mix formulations enriched with either turnip leaf powder or radish leaf powder at 5\% showed the maximum antioxidant activity i.e. 41.58 and $44.80 \%$, respectively. Moreover, the retention of antioxidant activity of the soup mixes enriched with turnip and radish leaf powders was superior as compared to the soup mixes enriched with either cauliflower and carrot leaf powder. The sensory characteristics of instant soup mix enriched with either turnip or radish leaf powder had comparable acceptability in comparison to the formulation where no leaf powder was incorporated, the overall acceptability ranged between 7.07 and 7.73. The instant soup mix supplemented with turnip leaf powder had superiority over radish leaf powder in terms of consumer acceptability and preference for purchase if available commercially. The turnip and radish leaf powder enriched soup mixes possessed an excellent antioxidant activity with optimum sensory characteristics and consumer acceptability, so suitable for the consumers who are looking for new foods with health benefits. Moreover, the appropriate use of unconventional vegetable leaves in the form of vegetable leaf powder can be an effective effort towards achieving the nutritional security of masses at low cost. Thus, it is recommended that the standardized instant soup mix formulations if incorporated in regular dietary patterns can be a healthy option for general masses owing to their high antioxidant activity in comparison to the soup mixes available in the market.

\section{References}

Abeysinghe, C.P., and Illeperuma, C.K. 2006. Formulation of an MSG (Monosodium Glutamate) free instant vegetable soup. Journal National Science Foundation of Sri Lanka. 34 (2): 91-95.

Chandramouli, P., Divya, V.S., Bharathi, Sivakami, A., Bharathiraja, B., and Jayamuthunagai, J. 2012. Standardization and nutritional analysis of soup powder prepared from Moringa oleifera, Solanum trilobatum, Centella asiatica. International Journal of Future Biotechnology. 1(1): 1-16.

Dehshahri, S., Wink, M., Afsharypuor, S, Asghari, G., and Mohagheghzadeh, A. 2012. Antioxidant activity in methanolic leaf extract of moringa peregrine (Forssk) fiori. Research in Pharmaceuticals Sciences. 7(2):111118.

El Wakeel, M.A. 2007. Ultra structure and functional properties of dry mixes of food. M.Sc. thesis, Faculty of Agriculture, Ain Shams University, Cairo.

Farzana, T., Mohajan, S., Saha, T., Hossain, M.N., and Haque, M.Z. 2017. Formulation and nutritional evaluation of soup powder supplemented with soy 
flour, mushroom, and moringa leaf. Food Science \& Nutrition. 5(4): 911920.

Janci Rani, P.R., and Sarojini, K.S. 2012. Nutrient content and total antioxidant activity in brahmi, moringa, amla dried powders and formulation of value added recipes. The Indian Journal of Nutrition and Dietetics. 49(7): 272-282.

Pandey, A.K., Dubey, R.K., Singh, V., and Vida, E. 2014. Addressing the problem of micronutrient malnutrition in $\mathrm{Neh}$ region-underutilized vegetables as a source of food. International Journal of Food Sciences and Nutrition. 3: 77-83.

Rekha, M.N., Yadav, A.R., Dharmesh, S., Chauhan, A.S., and Ramteke, R.S. 2010. Evaluation of antioxidant properties of dry soup mix extracts containing dill (Anthem sowa L.) leaf. Food and Bioprocess Technology. 3(3): 441-449.

Singh, S., Ghosh, S., and Patil, G.R. 1999. Development of mushroom-whey soup powder. International Journal of Food Science and Technology38(2): 217-224.
Singh, A., Grover, K., and Sharma, N. 2014. Nutritional evaluation of value added products using dehydrated greens for security of haematinic nutrient. Food Science Research Journal. 5(2): 168173.

Sunyoto, M., and Futiawati, R. 2012. The influence of full cream milk powder concentration on the characteristics of "rasi" instant cream soup. Journal of Agricultural Science and Technology. 2: 1218-1231.

Uusiku, N.P., Oelofse, A., Duodu, K.G., Bester, M.J., and Faber, M. 2010. Nutritional value of leafy vegetables of sub-Saharan Africa and their potential contribution to human health: a review. Journal of Food Composition and Analysis. 23(6): 499-509.

Wadikar, D.D., and Premavalli, K.S. 2013. Development of a hot water reconstitutable appetizer soup mix from Coleus aromaticus using response surface methodology. International Food Research Journal. 20(6): 30413046.

\section{How to cite this article:}

Nidhi Joshi, Kiran Bains and Harpreet Kaur. 2020. Evaluation of Antioxidant Activity of Developed Instant Soup Mixes using Vegetable Leaf Powders from Unconventional Greens. Int.J.Curr.Microbiol.App.Sci. 9(01): 711-721. doi: https://doi.org/10.20546/ijcmas.2020.901.077 